\title{
Correction to: The CoMirror algorithm with random constraint sampling for convex semi-infinite programming
}

\author{
Bo Wei ${ }^{1} \cdot$ William B. Haskell ${ }^{2}$ (D) S Sixiang Zhao $^{3}$ \\ ๑) Springer Science+Business Media, LLC, part of Springer Nature 2020
}

\section{Correction to: Annals of Operations Research https://doi.org/10.1007/s10479-020-03766-7}

This erratum is published as due to some technical error author names appeared reversed in the final publication.

Wei Bo to be read as Bo Wei

Zhao Sixiang to be read as Sixiang Zhao

Original publication has now been corrected.

Publisher's Note Springer Nature remains neutral with regard to jurisdictional claims in published maps and institutional affiliations.

The original article can be found online at https://doi.org/10.1007/s10479-020-03766-7.

William B. Haskell

wbhaskell@gmail.com

1 Institute of Operations Research and Analytics, National University of Singapore, Singapore 119007, Singapore

2 Krannert School of Management, Purdue University, West Lafayette 47906, USA

3 Sino-US Global Logistics Institute, Shanghai Jiao Tong University, Shanghai 200030, China 